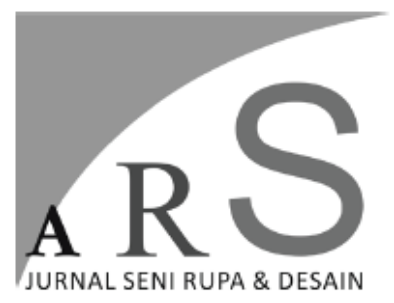

Volume 22 Nomor 3, Desember 2019

\section{ANALISIS ISI TEKS PENGANTAR KURATORIAL MIKKE SUSANTO ANTARA TAHUN 2000-2017}

\author{
Trisna Pradita Putra \\ Program Studi Tata Kelola Seni, Jurusan Seni Murni \\ Fakultas Seni Rupa, Institut Seni Indonesia Yogyakarta \\ e-mail: joseppradita@gmail.com
}

\begin{abstract}
ABSTRAK
Penelitian ini bertujuan untuk membuat pemodelan isi komunikasi kurator dalam teks pengantar kuratorial. Dari 110 pameran yang dikurasi Mikke Susanto, dipilih 10 pameran yang dinilai mewakili seluruh teks pengantar kuratorial yang pernah dibuat. Berdasarkan analisis isi terhadap 10 teks pengantar kuratorial karya Mikke Susanto, ditemukan bahwa setidaknya terdapat enam poin informasi utama yang disampaikan, yaitu: (1) latar belakang; (2) tujuan \& manfaat diselenggarakanya pameran; (3) konsep pameran; (4) seniman yang terlibat; (5) karya yang dipamerkan; dan (6) proses kreatif penyelenggaraan pameran. Hasil penelitian ini, diharapkan mampu berkontribusi sebagai salah satu referensi dalam proses pembelajaran mahasiswa untuk menyusun teks pengantar kuratorial. Hasil analisis ini juga dapat menjadi salah satu referensi pengembangan bahan ajar Mata Kuliah Kuratorial.
\end{abstract}

Kata kunci: analisis isi, teks pengantar kuratorial, Mikke Susanto

\begin{abstract}
This study aims at modeling the content of curator's communication delivered in the curatorial statement. Out of 110 exhibitions curated by Mikeke Susanto, 10 exhibition texts that were considered to be the representations of all were chosen. The content analysis applied to scrutinize them brought about a conclusion that there were six main points constituting those texts, namely:(1) background; (2) purpose(s) \& benefit(s) of the exbibition; (3) concept of the exhibition; (4) artist(s) involved; (5) works exhibited; and (6) creative process by which the exhibition is organized. The results of this study provide students with references in their practice to compile their own curatorial texts. Curriculum and material developers can also refer to it in creating contextual Curatorial Course teaching materials.
\end{abstract}

Keywords: content analysis, curatorial introductory texts, Mikke Susanto

\section{Pendahuluan}

Pada tahun 2009, Antara News meliput peristiwa pameran yang menarik di Semarang. Tulisan berjudul "Pameran Tanpa Kurator Bukan Masalah Besar" tersebut, membahas mengenai sebuah komunitas bernama "outsiders" yang menyelenggarakan pameran tanpa melibatkan seorang kurator. Peran kurator dinilai akan menghambat kreativitas para seniman, karena kurator akan membatasi karya mana yang boleh dan tidak boleh dipamerkan (https://www.antaranews.com/berita/148271 "pameran-tanpa-kurator - bukan - masalah besar," 2018). Pendapat ini memang mengandung unsur kebenaran, akan tetapi tidak utuh karena tidak sepenuhnya menggambarkan peran dan fungsi kurator. Kurator bukan hanya figur yang melakukan proses seleksi karya saja, melainkan juga berperan dalam hal penting lainnya.

Gabrielle Moser menyatakan bahwa kegiatan yang masuk dalam proses "kuratorial" telah berkembang menjadi sangat beraneka 
ragam. Mengatur penyelenggaraan pameran, menulis dan mempublikasikan esay kritis, menyusun serta menseleksi isian acara, mengkoordinasi fundraising, memimpin kunjungan ke studio, bahkan berbicara di depan publik tentang hasil kerja mereka adalah bidang yang identik dengan kurator (Moser, 2008: 27).

Kurator bukan hanya bertanggungjawab terhadap perkara teknis, tetapi masuk secara mendalam dalam urusan konseptual. Dalam konteks seni kontemporer, bahkan kurator dikatakan memiliki peranan penting untuk memproduksi makna artistik melalui penyelenggaraan pameran (Acord, 2010: 447). Berdasarkan pandangan ini maka dapat dikatakan bahwa berhasil atau tidaknya seniman mengkomunikasikan ide kepada khalayak dalam sebuah pameran, sangat ditentukan oleh peran kurator.

Pendapat tersebut sejalan dengan Ulrich Obrist yang menyatakan bahwa kurator adalah katalis yaitu sebagai pihak yang mempertemukan dan menyatukan seniman di satu sisi dan penonton di sisi lain (Susanto, 2004). Kurator berperan sebagai agen komunikasi yang bertugas menyampaikan ide seniman dalam karyanya kepada penonton yang mengapresiasi. Proses penyampaian pesan dilakukan melalui pemilihan tema, konsep pameran, karya, display, acara pembukaan, dan teks pengantar kuratorial. Teks pengantar kuratorial hampir selalu dipakai kurator untuk menyampaikan pesan kepada khalayak.

Salah satu teks pengantar kuratorial yang menarik untuk diteliti adalah teks kuratorial karya Mikke Susanto. Sejak berkarya menjadi kurator tahun 2000 sampai dengan tahun 2017, Mikke sudah mengkurasi 110 pameran (Wawancara: Mikke Susanto, 5 Maret 2018). Apabila dibuat rata-rata, maka setiap tahuh setidaknya Mikke mengkurasi 6 pameran. Jumlah ini menunjukkan bahwa sejak tahun 2000, Mikke secara konsisten menekuni profesi dan peran sebagai kurator. Mikke juga tercatat sebagai kurator koleksi Istana Negara dan sebagai dosen tetap di Jurusan Tata Kelola Seni ISI Yogyakarta yang secara spesifik mengajar kuratorial.

Kesadaran akan peran sebagai kurator yang harus dapat dipertanggungjawabkan secara akademis, membuat Mikke mempersiapkan teks pengantar kuratorialnya dengan baik dan terstruktur. Dengan melakukan Analisa terhadap apa saja isi pesan yang disampaikan Mikke dalam teks pengantar kuratorialnya, maka dapat dibuat pemodelan isi komunikasi Mikke Susanto dalam menjalankan peran sebagai kurator.

Penelitian ini berfokus untuk mengungkapkan apa saja isi pesan Mike Susanto sebagai kurator yang disampaikan melalui teks pengantar kuratorial. Diharapkan melalui penelitian ini dapat dihasilkan pemodelan isi pesan Mikke Susanto sebagai kurator dalam katalog pameran. Strategi komunikasi kurator menjadi data yang sangat penting untuk dipetakan agar dapat menjadi masukan berharga bagi kajian ilmu kuratorial itu sendiri serta sebagai panduan bagi pengembangan profesi kurator di kemudian hari.

Penelitian ini dilakukan terhadap 9 teks kuratorial pameran berskala nasional oleh Mikke Susanto. Sembilan teks kuratorial yang diteliti dinilai mewakili populasi 110 karya kuratorial Mikke. Berikut ini adalah kriteria pemilihan sampel teks kuratorial :

1. Teks pengantar kuratorial yang dimaksud adalah murni karya Mikke Susanto, bukan teks kurasi yang dihasilkan melalui kolaborasi dengan kurator lain.

2. Teks pengantar kuratorial dipilih mewakili kota tempat diselengarakan pameran. Setiap kota dipilih satu teks pengantar kuratorial.

3. Teks pengantar kuratorial dipilih berdasarkan skala pameran. Hanya pameran berskala sedang (regional) dan skala besar (Provinsi/Nasional) yang masuk dalam kriteria sampel.

Penelitian ini merupakan analisis isi kualitatif yang bersifat deskripstif eksploratif. Sekaran dan Bougie menyatakan, bahwa studi ekploratif dilakukan ketika situasi atau objek yang diteliti masih belum banyak diketahui, atau tidak ada informasi mengenai permasalahan dengan tema yang sama yang pernah terselesaikan di masa lalu (Sekaran and Bougie, 2009). Analisis isi adalah metode penelitian observasional yang digunakan untuk mengevaluasi konten-konten simbolis dari 
segala bentuk komunikasi yang terekam (Sekaran and Bougie, 2009). Teks pengantar kuratorial merupakan wujud komunikasi kurator kepada khalayak yang terekam dan dapat tersimpan dengan baik.

Sekaran and Bougie (2009) mengungkapkan bahwa analisis isi dibagi menjadi dua macam, yaitu analisis konseptual (conceptual analysis) dan analisis hubungan (relational analysis). Dalam analisis konseptual, data berupa teks akan dikodekan dalam kategori-kategori konten yang dapat dikelola. Sementara itu dalam analisis hubungan, hubungan antarkonsep yang ada dalam data tersebut akan diperiksa/diteliti agar dapat ditemukan makna. Penelitian ini menggunakan analisis konseptual, yaitu data komunikasi dalam teks pengantar kuratorial yang akan dikodekan dalam kategori-kategori tertentu.

Tipe analisis data yang digunakan dalam penelitian ini adalah analisis konseptual. Analisis konseptual dilakukan untuk menentukan kehadiran atau frekuensi konsep tertentu (seperti kata, tema, atau karakter) dalam sebuah teks. Dalam penelitian ini dilakukan analisis konseptual untuk memetakan isi informasi dalam teks pengantar kuratorial karya Mikke Sussanto. Isi komunikasi dalam teks pengantar kuratorial diidentifikasi berdasarkan kriteria tertentu sesuai dengan definisi yang ada.

Dalam tahap interpretasi data, hasil pengelompokan isi informasi teks pengantar kuratorial dikaji menggunakan sudut pandang komunikasi. Diharapkan melalui kajian isi pesan teks kuratorial ini temuan data dapat diperoleh pemodelan pola komunikasi Mikke Susanto sebagai kurator dalam teks pengantar kuratorialnya.

\section{Pembahasan}

Komunikasi dapat dikatakan adalah inti dari proses kekaryaan seorang seniman. Melalui karyanya, seniman mengkomunikasikan kegelisahan akan lingkungan sekitarnya, imajinasi dan ide, atau bahkan protes serta kritikan kepada pihak tertentu. Setiap ide dan gagasan dalam setiap karya kemudian dipresentasikan kepada publik melalui sebuah peristiwa bernama pameran seni. Hal ini sejalan dengan pendapat
Umberto Eco yang menyatakan bahwa pameran sebagai metoda komunikasi masa. Untuk lebih memahami fenomena komunikasi massa yang digunakan oleh seniman, kita akan menggunakan model komunikasi. Model komunikasi adalah representasi suatu fenomena, baik nyata maupun abstrak, dengan menonjolkan unsur-unsur terpenting fenomena tersebut (Mulyana, 2012: 133). Model komunikasi yang secara sederhana menggambarkan proses komunikasi dalam sebuah pameran adalah model komunikasi David K. Berlo (1960). Model komunikasi ini dikenal sebagai model SMCR, kepanjangan dari Source (sumber), Message (Pesan), Channel (Saluran), dan Receiver (Penerima). Selengkapnya detail dan keterangan mengenai model SMCR dapat dilihat pada gambar 1 .

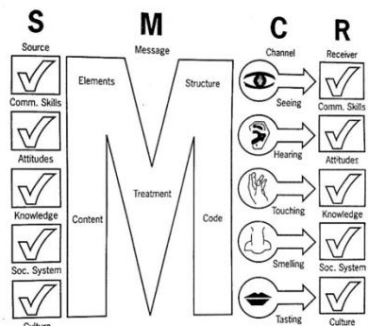

Gambar 1. Model Komunikasi SMCR

(Sumber: Burgoon, 1974: 16, dalam Mulyana 2012:163

Dalam model komunikasi SMCR, proses komunikasi sangat ditentukan oleh empat faktor penting, yaitu sumber pesan (Source), isi pesan (Message), media penyampai pesan (Channel), dan penerima pesan (Receiver). Keempat bagian ini harus saling mendukung satu dengan yang lain agar tujuan komunikasi berupa kesamaan makna dapat tercapai. Setiap faktor yang dalam komunikasi memuat unsurunsur penting yang menjadi penjabaran setiap faktor.

\section{Sumber Pesan (Source)}

Sumber pesan atau yang juga disebut sebagai komunikator adalah pihak yang menciptakan pesan. Sumber pesan dapat berupa orang atau kelompok orang. Sumber pesan atau encoder dapat menyampaikan pesan untuk dirinya sendiri atau juga dapat mewakili orang lain/lembaga. Dalam model SMCR sumber sangat dipengaruhi oleh 
beberapa faktor, yaitu keterampilan komunikasi, sikap, pengetahuan, sistem sosial, dan kebudayan. Semua faktor ini saling terhubung membentuk pribadi penyampai pesan yang sangat unik dan spesifik. Kepribadian ini nantinya akan sangat berpengaruh terhadap struktur pesan yang disampaikan dan media yang dipilih untuk menyampaikan pesan.

2. Isi Pesan (Message)

Isi pesan berasal dari pemikiran penyampai pesan. Dalam konteks pribadi, maka isi pesan adalah pandangan dan pikiran pribadi. Demikian pula dalam konteks kelompok, sumber pesan berasal dari pribadi yang diberi kepercayaan atau sekelompok pribadi yang sepakat dengan suatu pesan tertentu. Pesan dikembangkan dari beberapa unsur seperti elemen, isi, perlakuan, dan kode. Isi pesan adalah hal yang sangat menarik untuk diteliti dan dipetakan untuk mengungkapkan inti komunikasi yang dilakukan.

3. Media Penyampaian Pesan (Channel)

Penyampai pesan dapat menyampaikan ide dan gagasanya melalui berbagai medium yang ada. Medium komunikasi berkaitan erat dengan panca indera. Melalui kelima inderanya, mansia menerima berbagai stimulus dari lingkungan sekitarnya. Stimulus ini kemudian diolah dan dimaknai menjadi sebuah pesan yang berarti.

4. Penerima Pesan (Receiver)

Penerima pesan dalam konteks model komunikasi SMCR tidak terbatas hanya pada publik/komunikasi massa saja, namun juga komunikasi antar pribadi dan berbagai bentuk komunikasi tertulis (Mulyana, 2012: 168).

Jika kita cermati, faktor yang mempengaruhi sumber dan penerima pesan adalah sama yaitu: keterampilan komunikasi, sikap, pengetahuan, sistem sosial dan kebudayan. Para ahli berpendapat bahwa jika semua faktor tersebut memiliki tingkatan yang sama antara penyampai dan penerima pesan, maka komunikasi akan berjalan efektif. Karena itu komunikator yang baik akan berkomunikasi dengan strategi yang berbeda, tergantung dengan kondisi dan keunikan penerima pesan.
Model komunikasi SMCR memang tidak merepresentasikan semua bentuk komunikasi di dunia ini. Tetapi keunggulan meodel komunikasi ini memang mampu mengakomodasi baik konteks komunikasi interpersonal, maupun komunikasi massa baik langsung maupun tertulis. Dalam konteks seni (terutama seni rupa), model komunikasi SMCR ternyata mampu menggambarkan fenomena yang terjadi dalam proses komunikasi seniman dengan publiknya. Berikut ini adalah beberapa faktor yang menjadi penentu keberhasilan komunikasi dalam konteks seni rupa.

\section{Sumber Pesan (Source)}

Dalam konteks seni rupa (dan bidang seni lain), sumber pesan adalah seniman. Seniman merespon lingkungan atau mengeksplorasi ide baru dan menuangkannya dalam bentuk karya. Karya dalam hal ini adalah medium yang dipilih oleh seniman dalam mengartikulasikan ide dan gagasanya. Uniknya sering kali seniman tidak berkomunikasi secara langsung dengan publiknya. Tidak jarang peran endcoder dalam konteks komunikasi seniman kepada publik dilakukan oleh seorang kurator. Kurator memegang peranan penting dalam mengelola wacana dan menjadi jembatan komunikasi antara seniman dengan publik.

2. Isi Pesan (Message)

Seniman yang telah selesai menuangkan idenya dalam karya kemudian mempresentasikan karya kepada publik dengan sebuah momen pameran. Kurator sebagai pribadi yang ditunjuk, kemudian menjalankan peran dan fungsinya dengan mendesain isi pesan yang akan disampaikan. Isi pesan ini kemudin tertuang dalam judul pameran, seleksi kaya yang akan ditampilkan, dan yang sangat penting adalah teks pengantar kuratorial. Dalam teks pengantar kuratorial, kurator dapat menyusun rangkaian ide dan wacana kepada public secara sistematis dan jelas.

3. Media Penyampai pesan (Channe)

Banyak media yang dapat digunakan kurator untuk menyampaikan pesan kepada publik. Pesan dapat disampaikan melalui konsep pameran, judul, karya yang terseleksi, dan teks pengantar kuaratorial. Sebagai media 
yang paling kuat dalam menyampaikan gagasan inti pameran, teks pengantar kuratorial biasanya ditampilkan bersama dengan karya di ruang pamer dan tercetak dalam katalog.

4. Penerima Pesan (Receiver)

Penerima pesan dalam konteks seni rupa adalah kolektor dan semua pengunjung yang mengapresiasi karya. Penerima pesan dalam sebuah pameran biasanya sangat beragam dan berasal dari berbagai latar belakang. Keberagaman penerima pesan ini menjadi tantangan besar untuk kurator dalam menyampaikan pesan. Kurator harus membangun pesan sebaik mungkin, memanfaatkan semua media penyampaian pesan yang ada dan berkomunikasi secara cerdas.
Melihat pemaparan di atas, maka tidak dapat disangkal lagi bahwa peran kurator dalam sebuah pameran sangatlah penting. Kurator akan mendayagunakan baik skill berkomunikasi, sikap, pengetahuan, sistem sosial yang ada dan seperangkat kebudayaan yang dimiliki untuk membangun suatu pesan

yang utuh. Teks pengantar kuratorial adalah salah satu produk kreativitas kurator yang dapat diarsipkan dan diteliti kembali.

\section{Pembahasan}

Berdasarkan analisis Isi Pesan dalam teks pengantar kuratorial Mikke Susanto, terdapat enam kelompok besar sebagai berikut.

1. Latar belakang

\begin{tabular}{|c|c|c|}
\hline Jenis informasi & Judul pameran & Contoh penempatan \\
\hline Situasi negara & $\begin{array}{l}\text { Ksatria: } \\
\text { memahami } \\
\text { Tripama dan } \\
\text { Hastabrata } \\
\end{array}$ & $\begin{array}{l}\text { Pasca pilpres, negri ini membutuhkan sikap-sikap ksatria untuk kembali } \\
\text { menjadi manusai seutuhnya-utuhnya. }\end{array}$ \\
\hline $\begin{array}{l}\text { Situasi } \\
\text { kota/wilayah }\end{array}$ & Termogram & $\begin{array}{l}\text { Situasi global yang yang cukup kuat menerpa "perusahaan" milik dunia } \\
\text { itu (sebutan majalah tempo pada Bali) sebagai daerah yang sangat } \\
\text { bergantung pada pariwisata akhir-akhir ini terasa sangat melumpuhkan } \\
\text { denyut nadi kehidupan mereka. }\end{array}$ \\
\hline $\begin{array}{l}\text { Situasi ruang } \\
\text { seni/ tempat } \\
\text { diadakannya } \\
\text { pameran }\end{array}$ & $\begin{array}{l}\text { Outdoor } \\
\text { Sclupture } \\
\text { Exhibition } \\
\text { Bunga Bunga } \\
\text { Impian: } \\
\text { Respon Seni } \\
\text { untuk Alam }\end{array}$ & $\begin{array}{l}\text { International Cultural Centre (ICC) merupakan sebuah ruang pamer yang } \\
\text { menekankan hubungan alam budaya... } \\
\ldots \text {... singkatnya ruang berupa alam terbuka mengundang semua untuk } \\
\text { mengisi dengan segenap interpretasi dan makna. }\end{array}$ \\
\hline $\begin{array}{l}\text { Isu terkini } \\
\text { dalam dunia Seni }\end{array}$ & Harlequin & $\begin{array}{l}\text { Persoalan yang paling terasa begitu bergolak terletak pada seragamnya } \\
\text { tata visual dalam lukisan, maupun tak terbendungnya harga karya "perupa } \\
\text { pasar" (jika dibanding perupa yang dianggap bersejarah). Sepertinya saat } \\
\text { ini kita sedang berada dalam "kepanikan" sosial. Bukan saja panik harga, } \\
\text { namun juga panik situasi mau apa diri kita sekarang. }\end{array}$ \\
\hline Tokoh & $\begin{array}{l}\text { Ksatria: } \\
\text { memahami } \\
\text { Tripama dan } \\
\text { Hastabrata } \\
\end{array}$ & $\begin{array}{l}\text { Adalah pandawa: sang lima bersaudara dalam epik Mahabarata yang } \\
\text { selalu didengung-dengungkan sebagai ksatria. Pandawa dan para ksatria } \\
\text { lain di atas adalah kata kunci dalam pameran ini. Ksatria bukanlah sikap } \\
\text { yang bias, meskipun tidak pula diartikulasikan secara "tunggal". }\end{array}$ \\
\hline \multirow[t]{2}{*}{ Judul Pameran } & $\begin{array}{l}\text { After the affair art } \\
\text { project }\end{array}$ & $\begin{array}{l}\text { After the Affair adalah wadah sekaligus konsep imajiner tentang sebuah } \\
\text { hubungan antar individu. Sebuah perhelatan yang dimanifestasikan } \\
\text { sebagai ujud dari hasil pemikiran, vis- } \bar{a}-\text { vis perupa pada dunia individu } \\
\text { dan kota (intercosmos) }\end{array}$ \\
\hline & Realisme Banal & $\begin{array}{l}\text { Realis(me) banal adalah sebuah gambaran fenomena tentang terangkatnya } \\
\text { kembali eksistensi Realisme.... } \\
\text {.. Realisme yang menyertai konsep kurasi ini adalah berasal dari sudut } \\
\text { pandang historiografi tentang lahirnya Realisme di era paling awal. }\end{array}$ \\
\hline $\begin{array}{l}\text { Karakteristik } \\
\text { khusus seniman }\end{array}$ & $\begin{array}{l}\text { Pameran Seni } \\
\text { Lukis merayakan } \\
50^{\text {th }} \text { Mata Hitam } \\
\text { Jeihan }\end{array}$ & $\begin{array}{l}\text { "Kini saatnya, kita membuka mata hati, mata jiwa untuk melihat ke } \\
\text { belakang sekaligus ke depan. Mata hitam pada figur dalam lukisan-lukisan } \\
\text { Jeihan adalah rangkuman paling otentik dalam peradaban kita saat ini, } \\
\text { yang menembus ruang dan waktu" }\end{array}$ \\
\hline
\end{tabular}


2. Tujuan \& Manfaat

\begin{tabular}{|c|c|c|}
\hline Jenis informasi & Judul pameran & Contoh penempatan \\
\hline $\begin{array}{l}\text { Peran pameran } \\
\text { dalam menjawab } \\
\text { isu yang ada }\end{array}$ & \begin{tabular}{|l|} 
Pameran Seni \\
Lukis merayakan \\
$50^{\text {th }}$ Mata Hitam \\
Jeihan \\
\end{tabular} & $\begin{array}{l}\text { "jadi jelaslah bahwa "mata hitam” adalah ide masterpiece yang perlu } \\
\text { dirayakan” p.12 }\end{array}$ \\
\hline \multirow{2}{*}{$\begin{array}{l}\text { Konsep } \\
\text { inti/wacana yang } \\
\text { akan } \\
\text { disampaikan } \\
\text { melalui event } \\
\text { pameran }\end{array}$} & $\begin{array}{l}17 \mid 71: \text { Goresan } \\
\text { Juang } \\
\text { Kemerdekaan }\end{array}$ & $\begin{array}{l}\text { Tujuan dan semangat pameran ini didasari oleh kehendak untuk } \\
\text { menuturkan kebanggaan atas hak milik bangsa, berupa karya seni (lukis) } \\
\text { yang dihasilkan oleh manusia-manusia pilihan, pelukis-pelukis maestro } \\
\text { dan perupa-perupa ternama Indonesia P.10. }\end{array}$ \\
\hline & $\begin{array}{l}\text { Pameran seni } \\
\text { wayang } \\
\text { Ksatria : } \\
\text { Memahami } \\
\text { Tripama \& } \\
\text { Hastabrata }\end{array}$ & $\begin{array}{l}\text { Karenanya pameran ini menjadi kesempatan berharga untuk menyulut } \\
\text { kembali nilai-nilai ke-Indonesiaan, khususnya wacana mengenai jiwa } \\
\text { ksatria yang sesungguhnya telah kita dalami sejak lama. }\end{array}$ \\
\hline $\begin{array}{l}\text { Apa yang } \\
\text { diharapkan } \\
\text { dicapai melalui } \\
\text { pameran }\end{array}$ & $\begin{array}{l}17 \mid 71: \text { Goresan } \\
\text { Juang } \\
\text { Kemerdekaan }\end{array}$ & $\begin{array}{l}\text { Setidaknya pameran semacam ini diharapkan mampu menumbuhkan } \\
\text { kecintaan dan kebanggaan nasionalisme tetap terjaga di benak masyarakat } \\
\text { Indonesia, utamanya bagi generasi muda }\end{array}$ \\
\hline
\end{tabular}

\section{Konsep pameran : Judul/ tema pameran}

\begin{tabular}{|c|c|c|}
\hline Jenis informasi & Judul pameran & Contoh penempatan \\
\hline \multirow[t]{2}{*}{$\begin{array}{l}\text { Definisi dari } \\
\text { konsep/ } \\
\text { istilah yang } \\
\text { diungkapkan } \\
\text { dalam judul }\end{array}$} & $\begin{array}{l}17 \text { | 71: Goresan } \\
\text { Juang } \\
\text { Kemerdekaan }\end{array}$ & $\begin{array}{l}\text { Tepat pada tanggal } 17 \text { Agustus tahun ini, kemerdekaan Indonesia berusia } \\
71 \text { tahun. Angka } 1 \text { dan } 7 \text { memberi kenangan berharga bagi bangsa ini, } \\
\text { sebagai penanggalan yang identik dengan kemerdekaan. Jika angka itu kita } \\
\text { balik menjadi } 71 \text {, sumbu utamanya adalah peringatan kemerdekaan. } \\
\text { Selama } 71 \text { tahun Indonesia telah mampu memilih } 7 \text { presiden dengan } \\
\text { tetap mengedepankan } 1 \text { tujuan: negara ke-satu-an. }\end{array}$ \\
\hline & Realis(ME) Banal & $\begin{array}{l}\text { Realis (terutama dalam pameran ini) lebih banyak ditandai sebagai alasan } \\
\text { untuk menolak wadak atau realitas mentah. }\end{array}$ \\
\hline $\begin{array}{l}\text { Sejarah } \\
\text { perkembangan } \\
\text { konsep yang } \\
\text { dimaksud dalam } \\
\text { judul }\end{array}$ & Realis(ME) Banal & $\begin{array}{l}\text { Di samping itu Realisme pada awalnya juga digesek dengan munculnya } \\
\text { karya-karya, baik berupa litografi dan karikatur-karikatur - Honore' } \\
\text { Daumier (1808-1979) yang melahirkan unsur "protes" ketepatan anatomi } \\
\text { para pelaku dalam karyanya P.6. }\end{array}$ \\
\hline \multirow{3}{*}{$\begin{array}{l}\text { Maksud dari } \\
\text { tema }\end{array}$} & $\begin{array}{l}17 \text { | } 71: \text { Goresan } \\
\text { Juang } \\
\text { Kemerdekaan }\end{array}$ & $\begin{array}{l}\text { Narasi utama dari tema ini adalah mempertautkan wacana seni dan } \\
\text { kemerdekaan. }\end{array}$ \\
\hline & $\begin{array}{c}\text { Termogram } \\
93 / 03\end{array}$ & $\begin{array}{l}\text { "Termogram 93/03" Tidak hanya sebagai alat pengukur seberapa sampai } \\
\text { seberapa jauh peran mereka yang berpameran, namun juga sebagai } \\
\text { bentuk pengerahan intelektual yang dapat dimanfaatkan sejauh mungkin } \\
\text { sebagai bagian dari kajian kebudayaan yang lebih luas yang selama ini } \\
\text { mereka pelajari P10. }\end{array}$ \\
\hline & Harlequin & $\begin{array}{l}\text { Pameran ini meski bukan sebentuk "perlawanan" rualitas atas, setidaknya } \\
\text { merupakan tawaran agar para pemerhati tetap mendapat berita atas siklus } \\
\text { dan berbagai ragam ide, tema, dan visual dalam perkembangan terkini. }\end{array}$ \\
\hline
\end{tabular}

4. Seniman yang terlibat

\begin{tabular}{|c|c|l|}
\hline Jenis informasi & Judul pameran & \multicolumn{1}{c|}{ Contoh penempatan } \\
\hline $\begin{array}{c}\text { Ciri khas } \\
\text { seniman yang } \\
\text { terlibat }\end{array}$ & $\begin{array}{c}\text { Pameran Seni Lukis } \\
\text { merayakan 50 } \\
\text { Hitam Meihan }\end{array}$ & $\begin{array}{l}\text { Jeihan dikenal sebagai pelukis potret manusia bermata hitam. Mata } \\
\text { hitam yang ditorehkannya pada figur. }\end{array}$ \\
\cline { 2 - 3 } & Harlequin & $\begin{array}{l}\text { Sejumlah perupa yang hadir dalam pameran ini adalah mereka yang } \\
\text { tidak saja memiliki kegilaan ideologis, tetapi juga mencermati } \\
\text { sejumlah peluang yang mungkin untuk dihadirkan dalam } \\
\text { perkembangan saat ini. }\end{array}$ \\
\hline
\end{tabular}




\begin{tabular}{|c|c|l|}
\hline \multirow{3}{*}{$\begin{array}{c}\text { Latar belakang } \\
\text { seniman }\end{array}$} & Realis(me) Banal & $\begin{array}{l}\text { Di tahun-tahun terakhir ini ia (Handiwirman) memang intens } \\
\text { menggeluti dunia objek buatnya sendiri. Dari bahan yang } \\
\text { bervariasi: rambut, plastik, karet, benda keras, dan dengan teknik } \\
\text { membungkus, memintal, menganyam, menimbun, sampai kemudian } \\
\text { mencari hal yang paling menarik dari objek itu dan dilukisnya. }\end{array}$ \\
\cline { 2 - 3 } & $\begin{array}{l}\text { After the affair } \\
\text { art project }\end{array}$ & $\begin{array}{l}\text { Mereka setidaknya juga memiliki latar menarik, misalnya Ojite } \\
\text { adalah salah satu pendiri Sanggar Minat Universitas Malang (dulu } \\
\text { IKIP Malang), sedangkan Isa dan Fadjar adalah pengelola ruang } \\
\text { publik bernama Raos Gallery }\end{array}$ \\
\hline $\begin{array}{c}\text { Proses kekaryann } \\
\text { seniman }\end{array}$ & After the Affair & $\begin{array}{l}\text { Secara teknis, perupa dari Malang Raya telah melakukan kunjungan } \\
\text { keliling ke perupa mitra yang tinggal di Bali, Jogja \& Jakarta. Mereka } \\
\text { akan tinggal beberapa waktu dan melakukan serangkaian affair } \\
\text { dengan perupa mitra yang telah ditunjuk. }\end{array}$ \\
\hline $\begin{array}{c}\text { Kelompok/ } \\
\text { organisasi }\end{array}$ & Termogram & $\begin{array}{l}\text { Sanggar Dewata Indonesia (SDI) sebagai salah satu "volunteer" } \\
\text { perjuangan dengan spirit primordial Bali tentu memiliki hak untuk } \\
\text { menjawab persoalan di atas. }\end{array}$ \\
\hline
\end{tabular}

5. Karya yang dipamerkan

- karakteristik karya yang masuk

- klasifikasi karya

\begin{tabular}{|l|l|l|}
\hline Jenis informasi & \multicolumn{1}{|c|}{ Judul pameran } & \multicolumn{1}{c|}{ Contoh penempatan } \\
\hline $\begin{array}{l}\text { Karakteristik yang } \\
\text { masuk }\end{array}$ & $\begin{array}{l}\text { Pameran seni wayang } \\
\text { Ksatria : Memahami Tripama } \\
\text { \& Hastabrata }\end{array}$ & $\begin{array}{l}\text { Pameran ini menampilkan sejumlah wayang koleksi museum } \\
\text { sonobudoyo Yogyakarta dan koleksi pribadi Bapak Ir.Yuwono } \\
\text { Sri Suwito, M.M. }\end{array}$ \\
\cline { 2 - 3 } & Realis(Me) Banal & $\begin{array}{l}\text { Apa yang digulirkan Nurkholis dan Budi Kustarto dalam } \\
\text { karyanya adalah sebuah upaya mengangkat sejarah potret diri- } \\
\text { yang digambarkan secara realistik-menjadi bahan pewacanaan } \\
\text { bagi mereka. }\end{array}$ \\
\cline { 2 - 3 } & $\begin{array}{l}\text { Pameran Seni Lukis } \\
\text { merayakan 50 Mata Hitam } \\
\text { Jeihan }\end{array}$ & $\begin{array}{l}\text { Jika ditelusuri secara historis, sampai saat ini belum ditemukan } \\
\text { program atau pameran maupun perayaan berbasis ide. }\end{array}$ \\
\hline Klasifikasi karya $\mid 71:$ Goresan Juang & $\begin{array}{l}\text { Klasifikasi pertama, "koleksi yang dikerjakan oleh para } \\
\text { maestro seni Indonesia yang terkait dalam konteks perjuangan } \\
\text { bangsa" }\end{array}$ \\
\hline Realis(Me) Banal & $\begin{array}{l}\text { Inilah sebentuk Banalitas Subjek yang dilakukan oleh } \\
\text { perupa. } \\
\text { inilah banalitas objek yang mengakar pada satu persoalan: } \\
\text { apriori judgement. } \\
\text { Adapun Banalitas pola teknis dialami oleh Doel Ahmad } \\
\text { Besari, Hadi Soesanto juga nurkholis. } \\
\text { Sementara Ketut Suwidiarta, Agung “tato", Tatang BSP lebih } \\
\text { banyak mengisyaratkan banalitas persepsi. } \\
\text { Mereka sedang mengesplorasi banalitas pengalaman yang } \\
\text { sscara visual menghadirkan dimensi pencampur adukan } \\
\text { persoalan persoalan. }\end{array}$ \\
\hline
\end{tabular}

6. Proses kreatif penyelenggaraan pameran

\begin{tabular}{|l|l|l|}
\hline Jenis informasi & \multicolumn{1}{|c|}{ Judul pameran } & \multicolumn{1}{c|}{ Contoh penempatan } \\
\hline $\begin{array}{l}\text { Dinamika } \\
\text { persiapan }\end{array}$ & $\begin{array}{l}17 \mid 71 \text { : Goresan Juang } \\
\text { Kemerdekaan }\end{array}$ & $\begin{array}{l}\text { Sejak era Presiden Megawati Soekarno Putri upaya ini telah } \\
\text { digagas, namun berbagai kendala mengakibatkan } \\
\text { ketidakmungkinan terjadi... } \\
\text { Hingga pada awal 2015 muncul inisiatif dari Presiden Joko } \\
\text { Widodo untuk melakukan sosialisasi koleksi secara terbuka } \\
\text { dan dalam konteks “istana" sebagai inisiator. }\end{array}$ \\
\hline $\begin{array}{l}\text { Pelaksanaan } \\
\text { proses kreatif }\end{array}$ & After the Affair & $\begin{array}{l}\text { Setidaknya dalam affair ini, bagi mereka (Para perupa maupun } \\
\text { mitra) seperti menghadapi sebuah ujian emosi, aksi panggung } \\
\text { teater, menjalani hidup yang terekam selama 12 bulan. }\end{array}$ \\
\hline $\begin{array}{l}\text { Siapa saja yang } \\
\text { terlibat dalam }\end{array}$ & $\begin{array}{l}\text { 17 | 71: Goresan Juang } \\
\text { Kemerdekaan }\end{array}$ & $\begin{array}{l}\text { Maka pihak kementerian sekretariat Negara (yang menjadi } \\
\text { payung istana kepresidenan) bekerja sama dengan }\end{array}$ \\
\hline
\end{tabular}


proses kreatif
Kementerian Pendidikan \& Kebudayaan dibantu oleh sejumlah pihak terkait berupaya untuk mewujudkan pameran

\section{Kesimpulan}

Dari hasil analisis isi pesan dalam 9 teks pengantar kuratorial Mikke susanto, terdapat lima katagori informasi utama yang kemudian terbagi lagi menjadi beberapa bagian. Informasi yang termuat dalam teks pengantar kuratorial karya Mikke Susanto sebagai berikut

\section{Latar belakang}

Latar belakang memuat tentang permasalahan atau kondisi apa yang muncul, sehingga pameran perlu untuk diselenggarakan. Pemaparan latar belakang juga menjadi pijakan dasar untuk mengungkapkan alasan pemilihan konsep dan proses kurasi karya. Informasi dalam latar belakang terbagi kembali ke dalam beberapa subtema yaitu: '
a. Situasi negara
b. Situasi kota/wilayah
c. Situasi ruang seni/ tempat diadakanya pameran

d. Isu terkini dalam dunia Seni

e. Tokoh

f. Judul pameran

g. Karakteristik khusus seniman

2. Tujuan \& Manfaat diselenggarakanya pameran

Bagian ini memuat apa kontribusi pameran terhadap isu yang telah diapaparkan dalam latar belakang. Beberapa detail informasi yang ada dalam bagian ini adalah:
a. Peran pameran dalam menjawab isu yang ada.
b. Konsep inti/wacana yang akan disampaikan melalui event pameran.
c. Apa yang diharapkan dicapai melalui pameran.

3. Konsep pameran : Judul/ tema pameran Konsep pameran memuat narasi utama yang hendak dipresentasikan dalam pameran. Informasi yang masuk katagori Konsep pameran sebai berikut.
a. Definisi dari konsep/istilah yang diungkapkan dalam judul.
b. Sejarah perkembangan konsep yang dimaksud dalam judul.
c. Maksud dari tema.

\section{Seniman yang terlibat}

Pada bagian ini, kurator menjelaskan mengenai seluk beluk seniman yang terlibat dalam pameran. Berikut adalah detail informasi yang termuat dalam bagian ini, yaitu:
a. Ciri khas seniman yang terlibat.
b. Latar belakang seniman.
c. Proses kekaryaan seniman.
d. Kelompok/ organisasi.

5. Karya yang dipamerkan

Bagian ini membahas mengenai seluk beluk karya yang dipamerkan. Detail informasinyang disajikan sebagai berikut:
a. Karakteristik karya yang masuk.
b. Klasifikasi karya.

6. Proses kreatif penyelenggaraan pameran Bagian ini membahas mengenai proses kerja di belakang layar penyelenggaraan pameran. Berikut ini adalah detail informasi yang ditampilkan:
a. Dinamika persiapan.
b. Pelaksanaan proses kreatif.
c. Siapa saja yang terlibat dalam proses kreatif.

Berikut ini adalah peta informasi dalam teks kuratorial Mikke Susanto

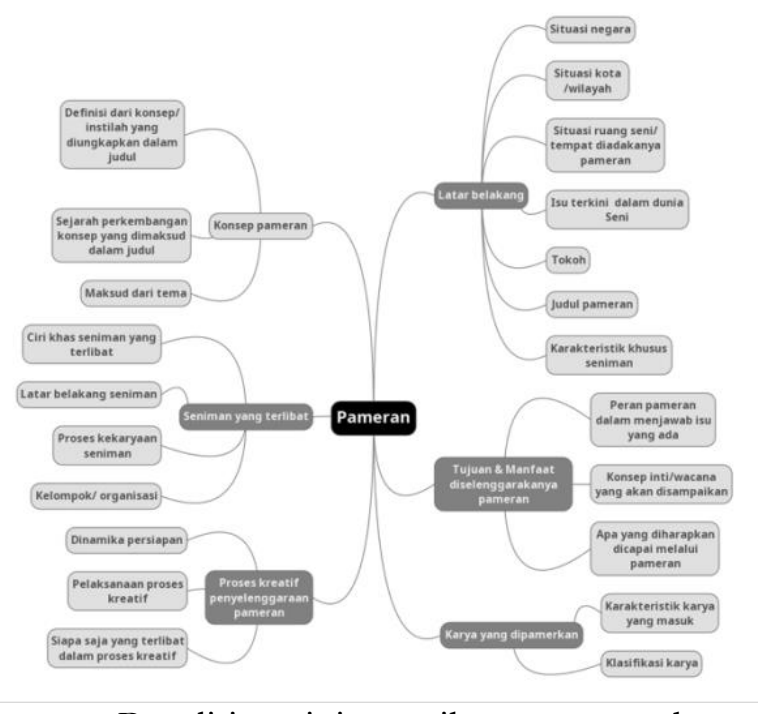

Penelitian ini masih sangat terbatas meneliti satu kurator yaitu Mikke Susanto, karena itu penting bagi peneliti berikutnya untuk meneliti pola komunikasi kurator lain, 
sehingga gaya penulisan antar kurator dapat dipetakan.

\section{Daftar Pustaka}

Kyzrs Acord, S. (2010). No Title. Qual Sociol, 447.

Moser, G. (2008). No Title. International Contemporary Art, 27.

Mulyana, D. (2012). Ilmu Komunikasi: Suatu Pengantar. Bandung: PT. Remaja Rosda Karya.

pameran-tanpa-kurator - bukan - masalah besar. (2018).

Sekaran, U., Bougie, R. (2009). Reseach Method for Bussines (15th Editi). UK: John Wiley $\&$ Sons Ltd.

Susanto, M. (2004). Menimbang Ruang Menata Rupa. Yogyakarta: Galang Press.

\section{Webtografi}

https://www.antaranews.com/berita/148271/ pameran-tanpa-kurator-bukan-masalah-besar, Diakses 8 April 2018

\section{Wawancara}

Wawancara dengan Mikke Susanto 5 Maret 2018, dan didukung data arsip teks pengantar kuratorial 
Trisna Pradita Putra, Analisis Isi Teks.. 